Supplement of Biogeosciences, 17, 6377-6392, 2020

https://doi.org/10.5194/bg-17-6377-2020-supplement

(C) Author(s) 2020. This work is distributed under

the Creative Commons Attribution 4.0 License.

(c) (1)

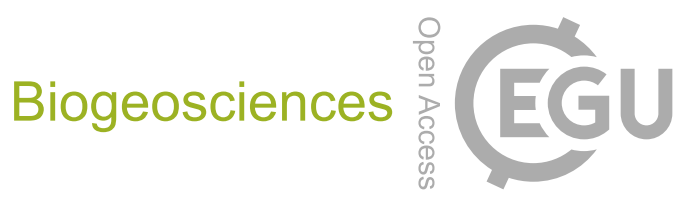

Supplement of

\title{
Root uptake under mismatched distributions of water and nutrients in the root zone
}

\section{Jing Yan et al.}

Correspondence to: Teamrat A. Ghezzehei (taghezzehei@ucmerced.edu)

The copyright of individual parts of the supplement might differ from the CC BY 4.0 License. 


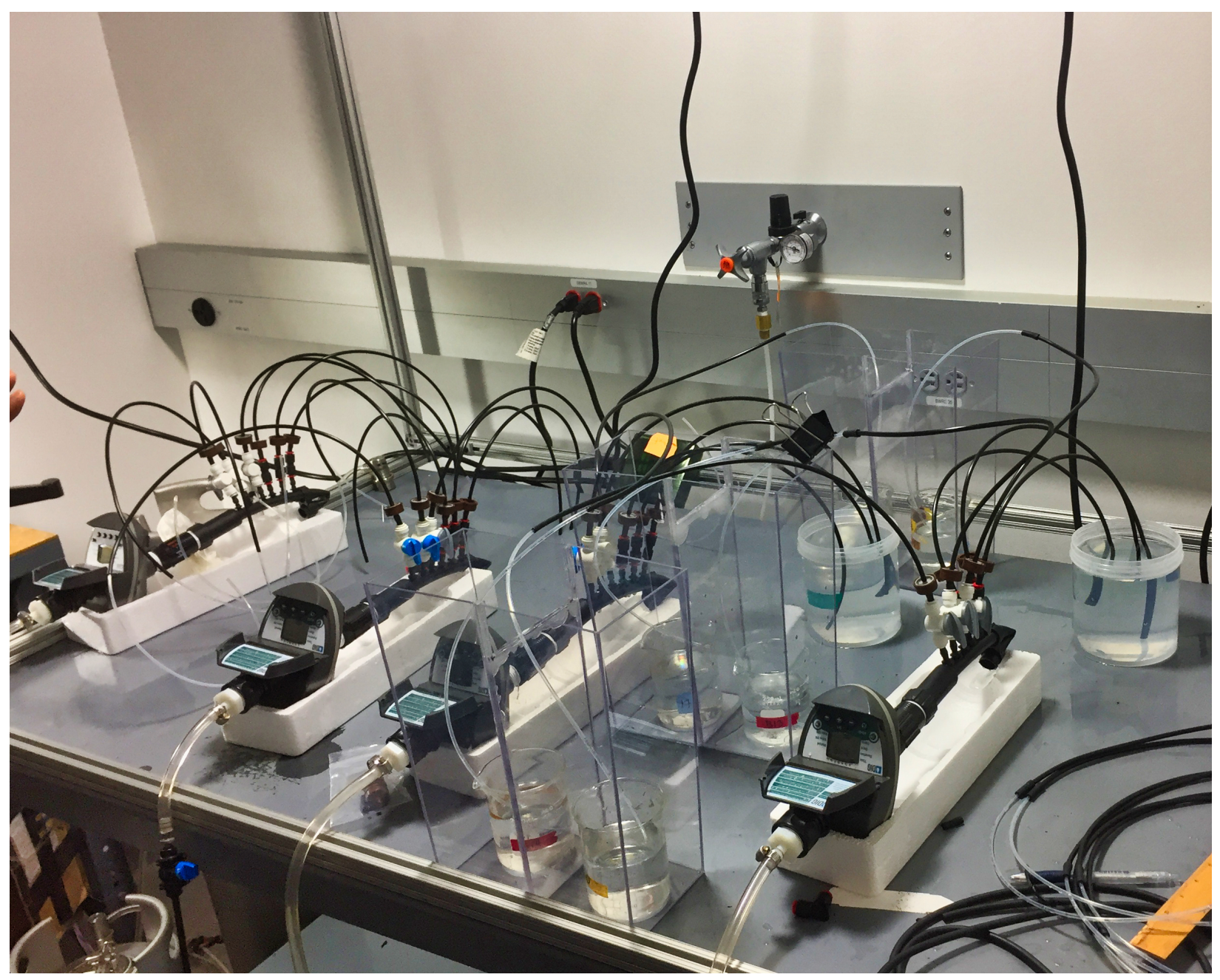

Figure 1. Testing and calibration of individual water dripper tips. 


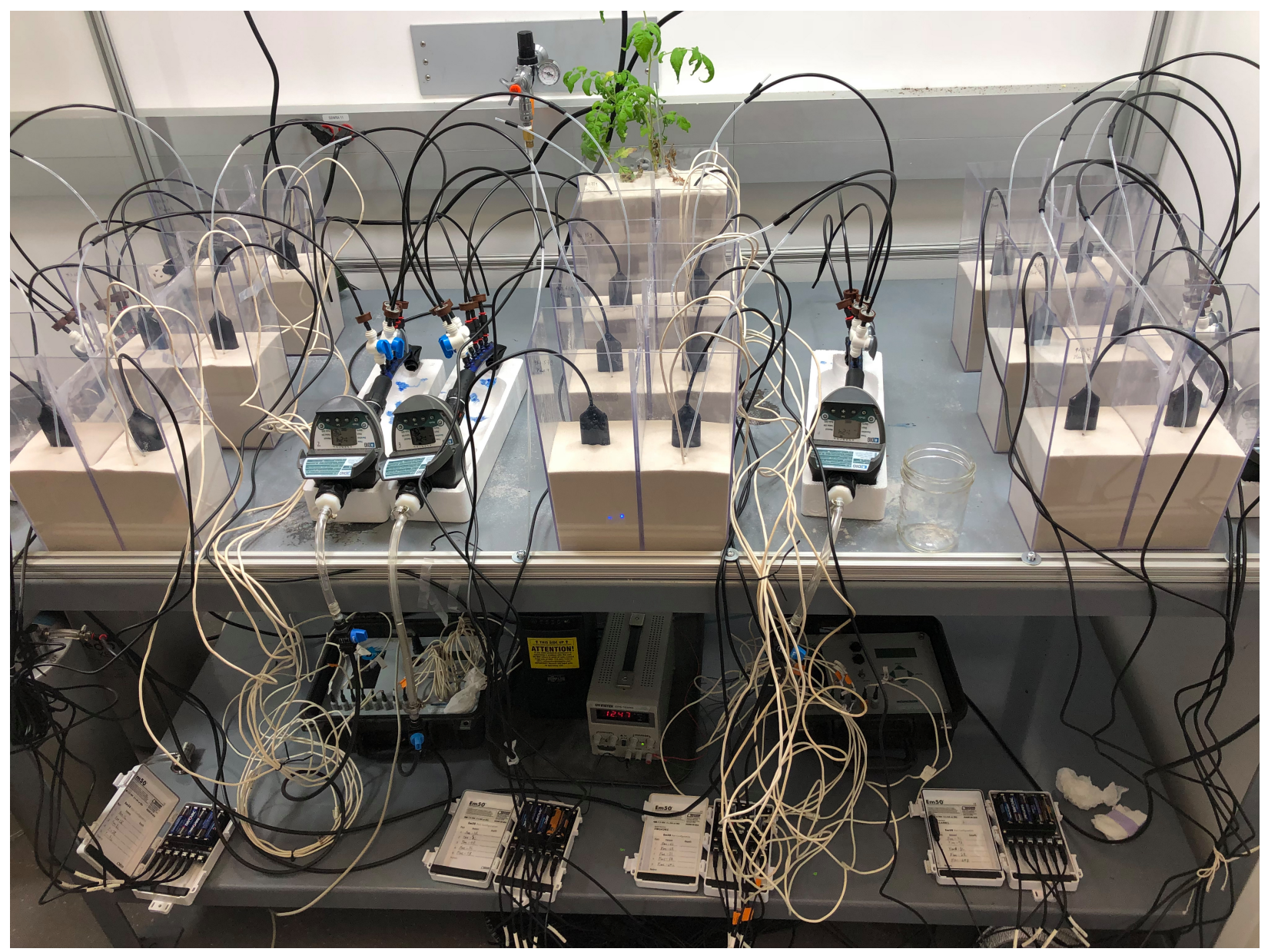

Figure 2. Placement of water content sensors, psychrometers, and irrigation tubes. Digital irrigation timers connected to pressurized water supply tubes are shown between pots. Data loggers and constant voltage supply for psychrometers were placed on the bottom shelf. Indoor growth lights were placed above the plants. Note that a plant that was not included in the current study was also shown in the middle row. 


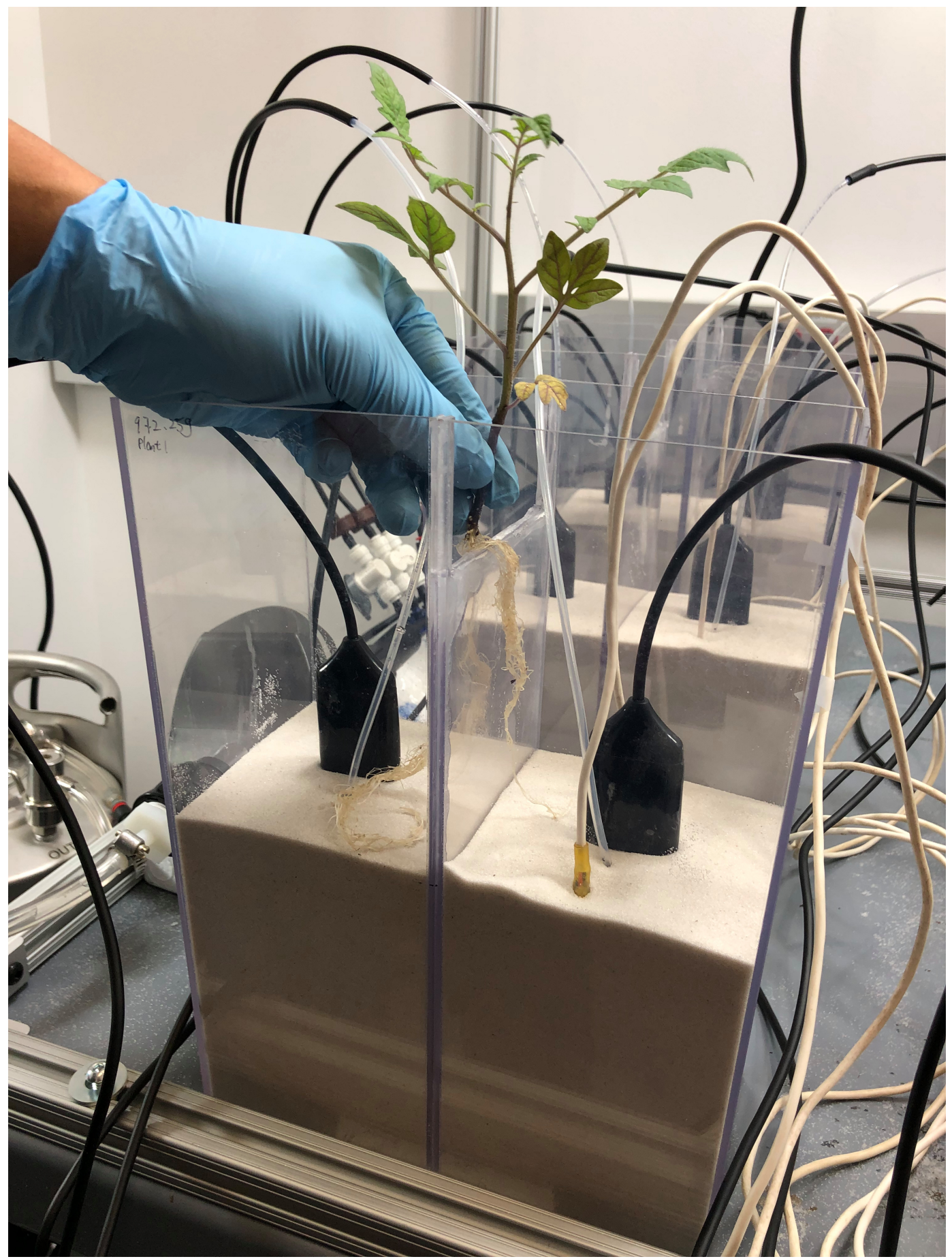

Figure 3. Transplanting of seedlings to split pots. Pre-installed sensors and irrigation tubes are visible. 


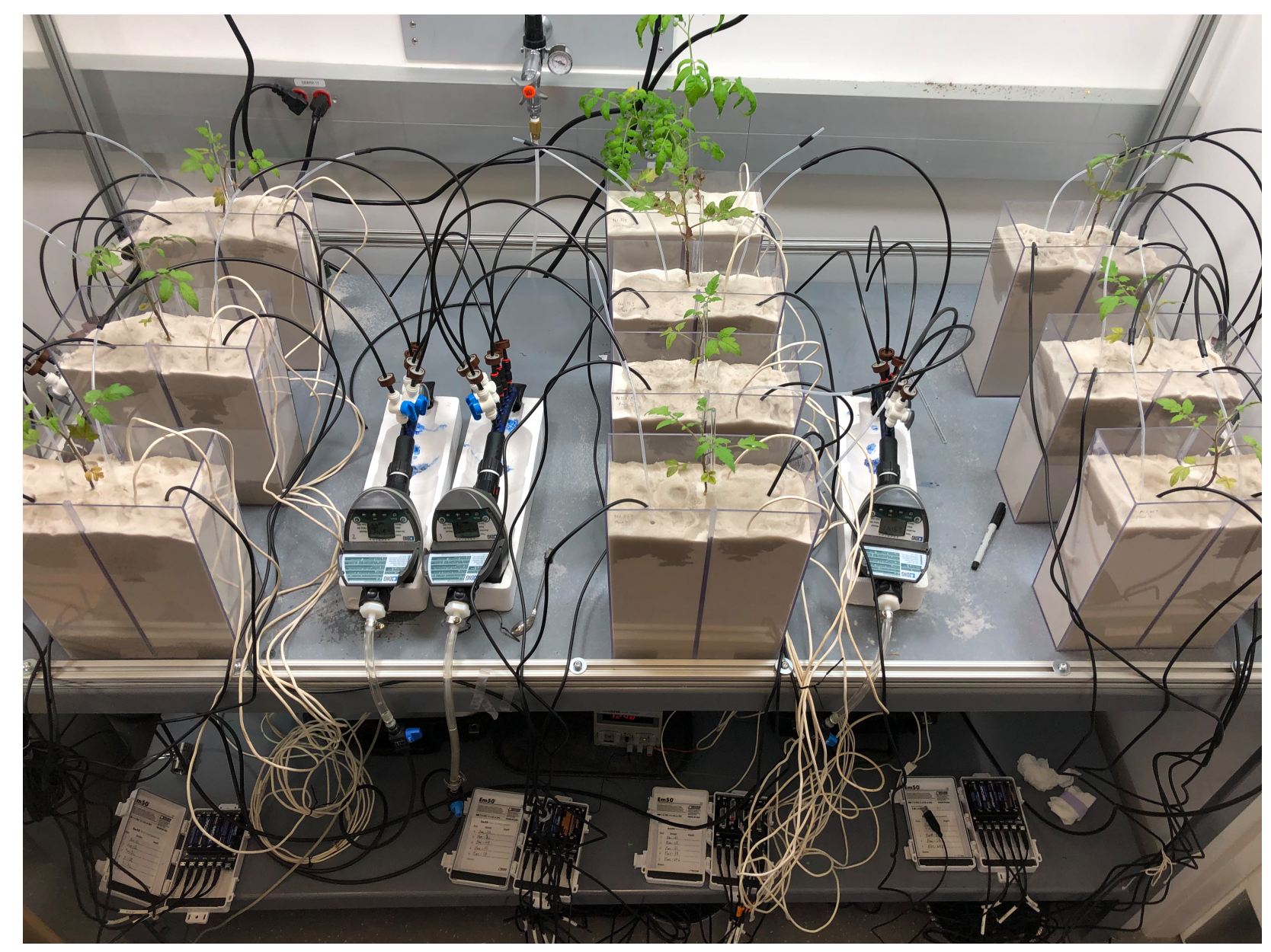

Figure 4. Irrigation on Day 1 after the transplantation. 


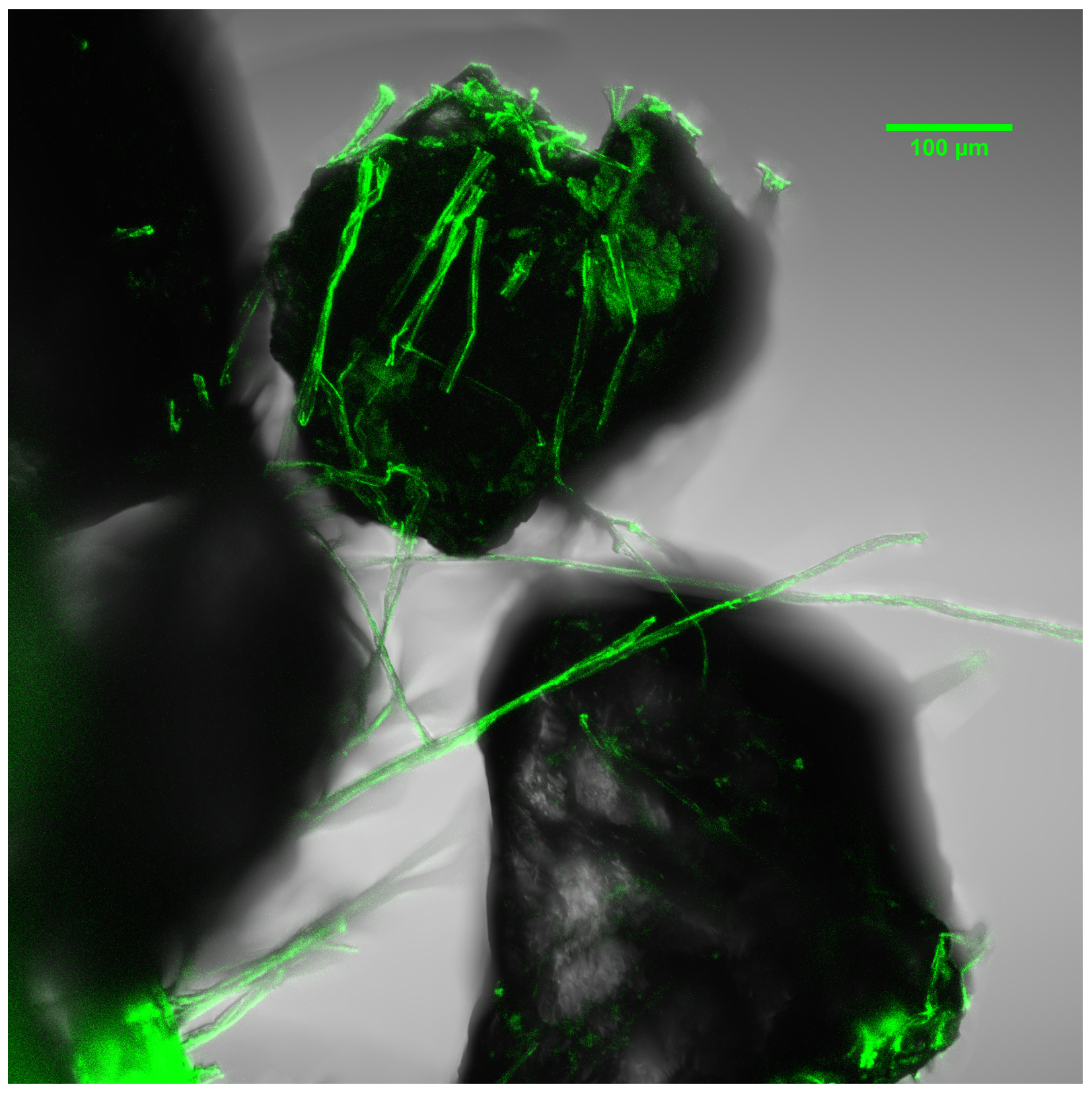

Figure 5. Confocal microscopic image of extensive fluorescent organic coating (depicted in green) on the surface of the sand particles inside the rhizosheath in the "Dry" compartment of treatment $\mathbf{D}$. 

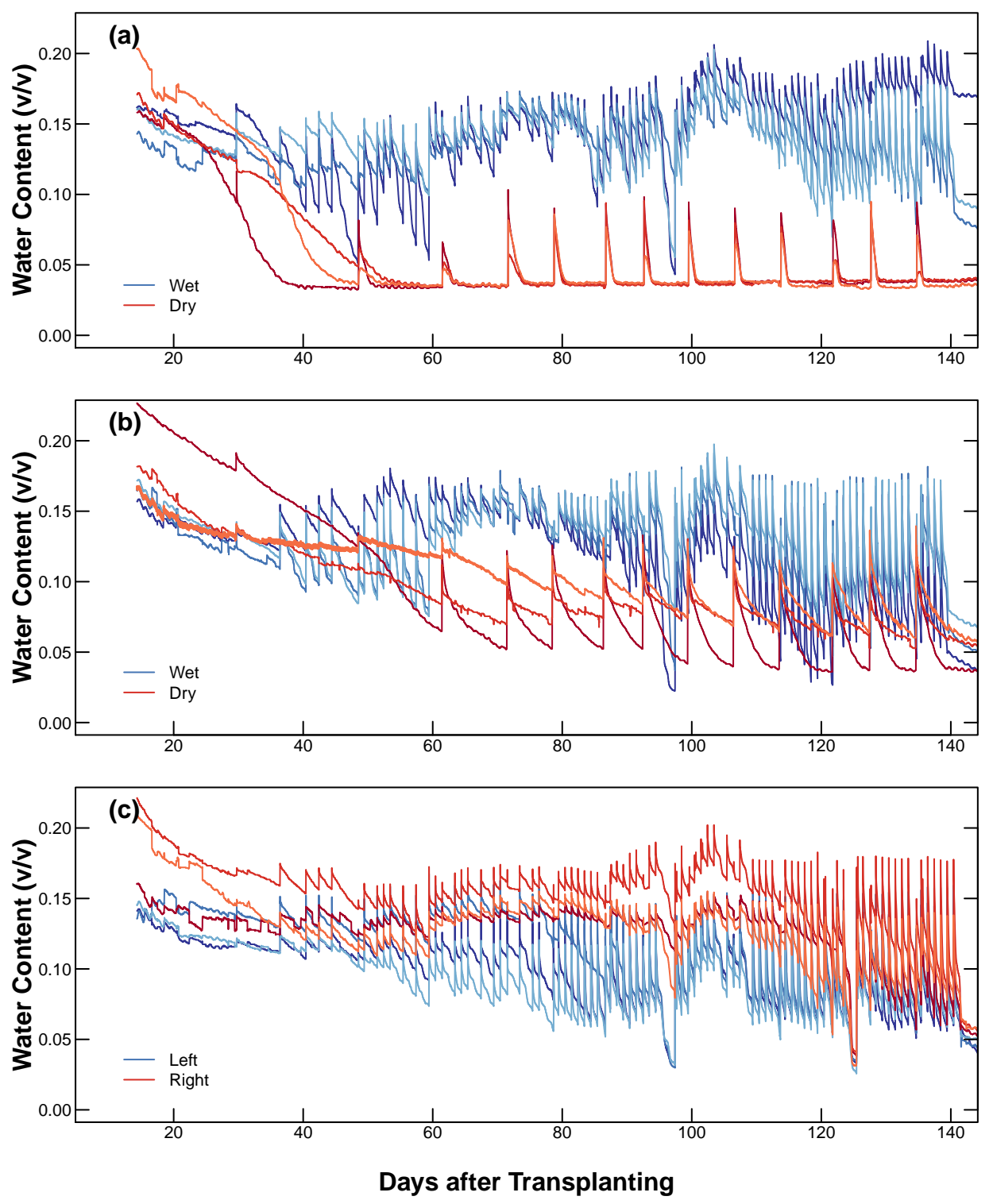

Figure 6. Long-term temporal changes in volumetric water content in different compartments of treatment D (a), C1 (b) and C2 (c) from day 4 to 149 after transplantation. 

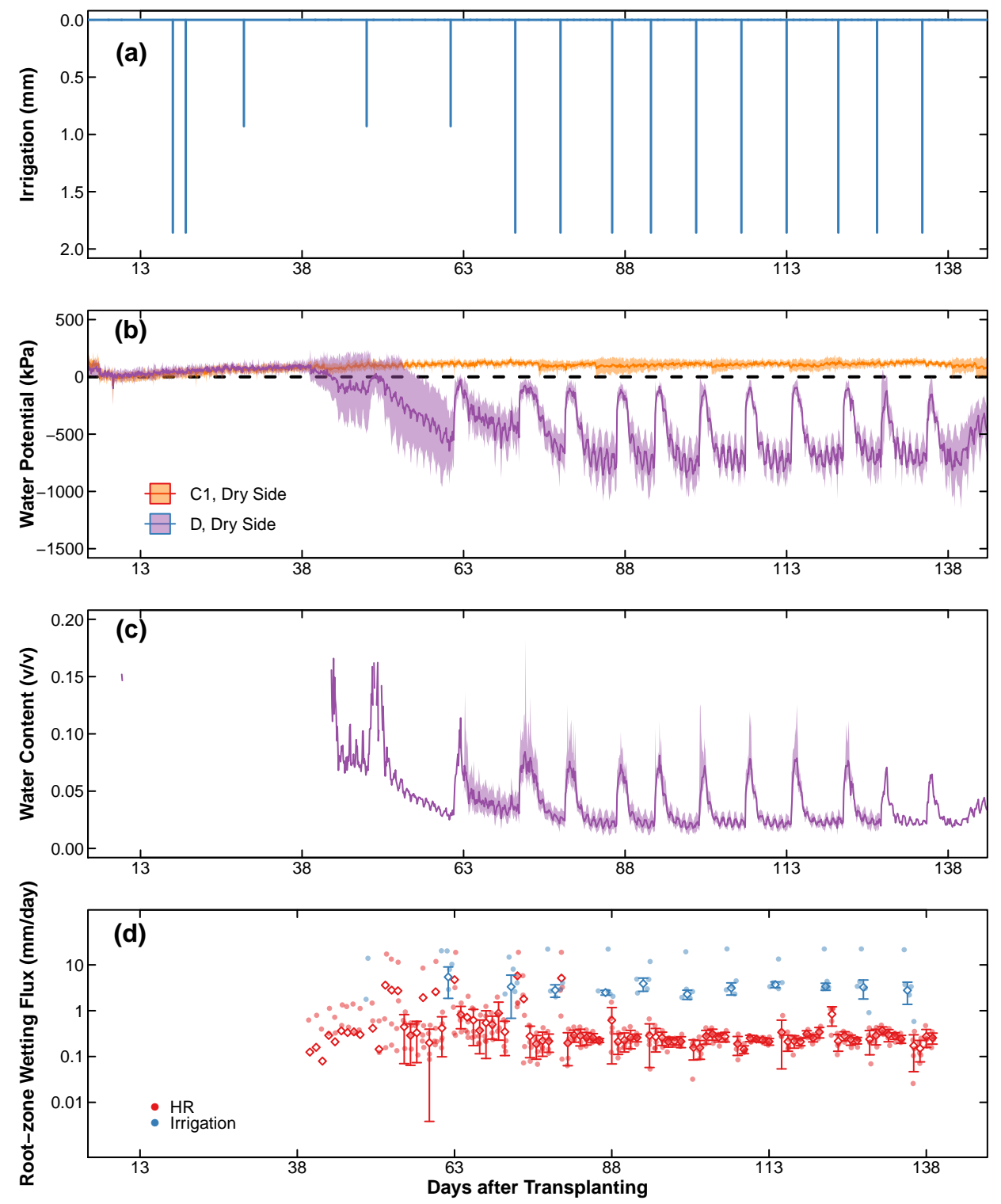

Figure 7. Wetting schemes (a) and temporal changes in water potential (b) in the "Dry" compartment of treatment D and C1; temporal changes in water content (c) and root-zone wetting flux (d) converted using water retention curves from day 4 to 149 after transplantation. Note that the results of water potential in the dry compartment of treatment $\mathbf{C 1}$ were plotted only for the demonstration of sensor validity. They do not represent the actual water potential in the root zone because of the soil never dried to the measurment range of psychrometers $(\psi<-50 k P a)$. 